\title{
Evaluation of Yield and Energy of Greenhouse Tomato Production in Each Asian Monsoon Area Using Cultivation Simulator Considering Growth Condition
}

\author{
Seiji MATSuO ${ }^{1 *}$, Toyohisa FuJITA ${ }^{1}$, and Yasubaga IWASAKI ${ }^{2}$ \\ ${ }^{1}$ School of Engineering, the University of Tokyo, 7-3-1 Hongo, Bunkyo-ku, Tokyo 113-8656, Japan \\ ${ }^{2}$ National Agriculture and Food Research Organization, 3-1-1 Kannondai, Tsukuba, Ibaraki 305-8517, Japan
}

\begin{abstract}
In recent years, the Asian monsoon region has a large business opportunity for the global food market for Japan. In this study, the authors evaluated the crop growth conditions and energy of greenhouse tomato production in several Asian monsoon areas. In these evaluations, a cultivation simulator considering growth conditions was used. In the calculation of the energy required to maintain the cultivation environment of the greenhouse, the photosynthesis rate of the plants and the transpiration rate were also calculated by simulation. As a result, the difficulty of greenhouse tomato production under high temperature and humidity conditions in Asia and the differences in crop growth conditions among these regions could be clarified by this analysis. In the future, it was suggested that it would be necessary to reduce the temperature of the greenhouse while maintaining the amount of photosynthesis.
\end{abstract}

\section{Introduction}

In recent years, the Asian monsoon region has a large business opportunity for the global food market for Japan. However, under severe conditions of high temperature and humidity, it is necessary to understand and control the cultivation environment in order to cause hightemperature injury in the process of crop growth (Nakano, A. 2016). The high temperature environment increases the energy required to control the cultivation conditions to maintain ideal cultivation conditions. Therefore, it is thought that it is important for cultivation management to cope with this while securing a high-level crop sufficiently.

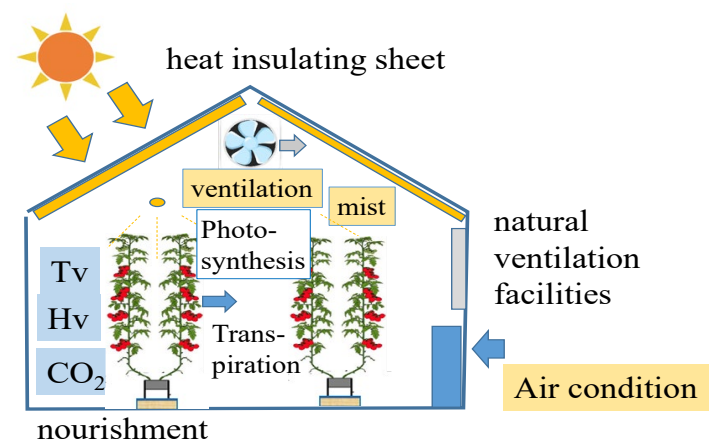

Figure 1. Appearance of tomato cultivation greenhouse

In this study, the authors evaluated the crop growth conditions and energy of greenhouse tomato production in several Asian monsoon areas (Figure 1). In these evaluations, a cultivation simulator considering growth conditions was used. This simulator is constructed from three processes of leaf photosynthesis, distribution of photosynthetic components, and fruit growth in order to analyse growth conditions in detail.

In the calculation of the energy required to maintain the cultivation environment of the greenhouse, the photosynthesis rate of the plants and the transpiration rate were also calculated by simulation and used to analyse the heat balance in the greenhouse. In the evaluation of the growth condition, effects of temperature conditions on fruit development were examined in tomato with different planting seasons and in each fruit truss. Changes in air temperature in greenhouses in each region of Asia during planting and harvesting were investigated from weather data.

\section{Mathematical Model of Tomato Cultivation Simulator}

Figure 2 shows an overview of the system used for tomato yield prediction. In modeling, based on the tomato model that has already been proposed (Jones et al., 1991), this system consists of three units to estimate the tomato yield in the greenhouse: photosynthetic rate in leaves, fruit distribution, fruit enlargement. In the description of the model, a system in which a delay element was added to a simple stock and flow model based on the sink source model was used. The main mathematical models used in

\footnotetext{
Corresponding author: smatsuo@sys.t.u-tokyo.ac.jp
} 
these processes and the calculation of energy consumption are expressed as follows:

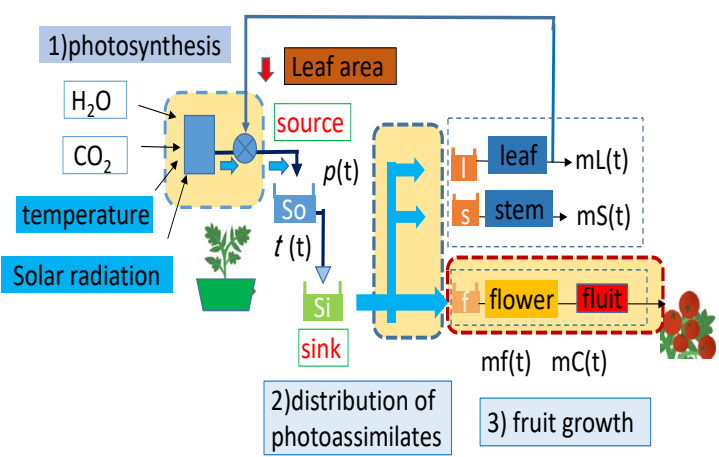

Figure 2. Overview of tomato yield prediction system

1) Photosynthetic rate, (photosynthesis in leaves),

The method of combining photosynthesis, stomatal conductance and leaf temperature models proposed by KIM was used for calculation of photosynthetic rate (Kim and Lieth, 2003). The FvCB (Farquhar, von Caemmerer and Berry) model is used for photosynthetic rate, the BWB (Ball, Woodrow and Berry) model is used for stomatal conductance, and the energy balance model is used for leaf temperature and transpiration.

The photosynthesis rate $A\left(\mu \mathrm{mol} \mathrm{m} \mathrm{m}^{-2} \mathrm{~s}^{-1}\right)$ is expressed by the equation (1).

$$
A=\min \left\{A_{c}, A_{j}, A_{p}\right\}-R_{d}
$$

where, $A_{\mathrm{c}}, A_{\mathrm{j}}$, and $A_{\mathrm{p}}$ are the photosynthetic rates in the saturated, rate-limiting, and phosphate-limited states, respectively, and $R_{\mathrm{d}}\left(\mu \mathrm{mol} \mathrm{m} \mathrm{m}^{-2} \mathrm{~s}^{-1}\right)$ is the mitochondrial respiration rate. These are functions of leaf temperature and carbon dioxide concentration in the leaf.

The stomatal conductance $g_{s}\left(g^{-2} \mathrm{~s}^{-1}\right)$ is expressed by equation (2).

$$
g_{s}=\mathrm{b}+\mathrm{m} \cdot \mathrm{A} \cdot h_{s} /\left(\mathrm{C} s / P_{a}\right)
$$

where, $h_{\mathrm{s}}(-)$ is the relative humidity at the leaf surface, $C$ s ( $\mu$ bar) is the carbon dioxide concentration at the leaf surface, $\mathrm{Pa}(\mathrm{kPa})$ is the atmospheric pressure and $\mathrm{b}$ and $\mathrm{m}$ are constants. In this study, the stomatal conductance has been improved to the model considering state of humidity in the air as shown in Eq. (3), considering high temperature and high humidity conditions in Asia.

$$
g_{s}=\mathrm{b}+\mathrm{m} \cdot \mathrm{A} \cdot 1 /\left(1+D / \mathrm{D}_{0}\right) \cdot 1 /\left(\mathrm{Cs} / P_{a}\right)
$$

where, $D\left(\mathrm{~g} / \mathrm{m}^{3}\right)$ represents the humidity deficit, it is the difference (deficit) between the amount of moisture in the air and how much moisture the air can hold when it is saturated and $\mathrm{D}_{0}$ is a constant parameter.

The transpiration rate $E_{v}\left(\mathrm{~g} \mathrm{~m}^{-2} \mathrm{~s}^{-1}\right)$ is expressed by the equation (4).

$$
E_{\mathrm{v}}=18 \cdot g_{v} \cdot\left(\left(e_{s}\left(T_{L}\right)-e_{a}\right) / P_{a}\right)
$$

where, $e_{\mathrm{s}}(\mathrm{kPa})$ and $e_{\mathrm{a}}(\mathrm{kPa})$ are saturated water vapor pressure of leaf surface and cultivation environment, $\mathrm{Pa}$ is atmospheric pressure and $T_{\mathrm{L}}\left({ }^{\circ} \mathrm{C}\right)$ is leaf temperature. Leaf temperature is expressed by equation (5) based on the Energy Balance model for leaf temperature and heat balance.

$$
R \downarrow-R \uparrow+L \downarrow-L \uparrow=\rho l \cdot C_{p l} \cdot g_{b} \cdot\left(T_{L}-T_{v}\right)
$$

where, $R\left(\mathrm{~W} \mathrm{~m}^{-2}\right)$ is shortwave radiation, $L\left(\mathrm{~W} \mathrm{~m}^{-2}\right)$ is longwave radiation, $\rho_{l}\left(\mathrm{~kg} \mathrm{~m}^{-3}\right)$ is specific gravity of air, $C_{\mathrm{pl}}\left(\mathrm{J} \mathrm{kg} \mathrm{k}^{-1} \mathrm{C}^{-1}\right)$, is specific heat of air, and $T_{\mathrm{v}}\left({ }^{\circ} \mathrm{C}\right)$ is temperature of cultivation environment.

In the Kim and Lieth model, the photosynthetic rate and the transpiration rate are calculated by programming an algorithm for calculating the intersection point by repetition as shown in Figure 3.

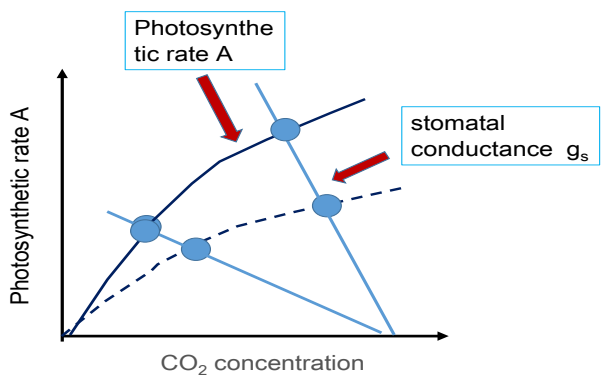

Figure 3. Calculation method of photosynthetic rate

\section{2) Distribution of photoassimilates}

Carbohydrates generated by photosynthesis of the source leaves are translocated to various sink organs such as roots, leaves, and seeds for use and accumulation (Kurosaki et al., 2014). The mathematical model of the stock and flow model based on the sink and source model is as follows. The proposed mathematical model using stock and flows based on sink and source models is as follows. Amount of photosynthesis is distributed for the formation of leaves, stems and flowers. The amount of photosynthesized is distributed to each organ as shown in the following equation. These are particularly affected by temperature. The photosynthetic products by translocation are distributed to each organ as shown in the following equation.

$$
\begin{aligned}
& d S o / d t=\mathrm{mLa}(\mathrm{t}) A(t)-\mathrm{t}_{\mathrm{r}} S o(t) \\
& d S i / d t=\mathrm{tr}_{\mathrm{r}} S o(t-L \mathrm{i})-\mathrm{g}(T) S i(t) \\
& m i_{l, s, f}(\mathrm{t})=\mathrm{D}_{\mathrm{L}, \mathrm{s}, \mathrm{f}} \mathrm{Z}(\mathrm{T}) \mathrm{g}(T) S i(t)
\end{aligned}
$$

Where, So $(\mu \mathrm{mol})$ is the amount of photosynthesis stored in the source, $\mathrm{mLa}$ is the leaf area $\left(\mathrm{m}^{2}\right)$, $\operatorname{tr}$ is the translocation rate $(\mu \mathrm{mol} / \mathrm{s}), \mathrm{A}\left(\mu \mathrm{mol} \mathrm{m}^{-2} \mathrm{~s}^{-1}\right)$ is photosynthesis rate, $\mathrm{Si}(\mu \mathrm{mol})$ is the amount of 
photosynthesis transferred to the sink, $\mathrm{g}(\mathrm{T})(\mu \mathrm{mol} / \mathrm{s})$ is the rate of movement to the organ, which is affected by temperature. $\mathrm{Li}(\mathrm{s})$ is the time delay in the translocation. $\mathrm{D}_{\mathrm{L}}(-), \mathrm{D}_{\mathrm{L}}(-)$ and $\mathrm{D}_{\mathrm{L}}(-)$ are distribution coefficients to leaf $m l i(\mu \mathrm{mol})$, stem $m s i(\mu \mathrm{mol})$, and flower $m f i$ ( $\mu \mathrm{mol})$, which are also affected by temperature.

\section{3) Growth fluits}

Logistic curves are used to describe the growth of crops such as tomatoes.

$$
\begin{aligned}
& m L(\mathrm{t})=1 /\left(1+\exp \left(-\mathrm{a}_{\mathrm{L}} m i_{I}(\mathrm{t})\right)\right) \\
& m S(\mathrm{t})=1 /\left(1+\exp \left(-\mathrm{a}_{\mathrm{s}} m i_{s}(\mathrm{t})\right)\right) \\
& m F(\mathrm{t})=1 /\left(1+\exp \left(-\mathrm{a}_{\mathrm{F}} \operatorname{mif}(\mathrm{t})\right)\right) \\
& m C(\mathrm{t})=1 /(1+\exp (-\mathrm{a} m F(\mathrm{t})))
\end{aligned}
$$

Where, $\mathrm{a}_{\mathrm{L}}(-)$, $\mathrm{a}_{\mathrm{S}}(-)$ and $\mathrm{a}_{\mathrm{F}}(-)$ are constant value, $m L$ $(\mu \mathrm{mol}), m S(\mu \mathrm{mol}), \mathrm{mF}(\mu \mathrm{mol})$, and $\mathrm{mC}(\mu \mathrm{mol})$ indicate the total amount of leaves, stems, flower and crop, respectively.

In addition, the enlargement rate of the fruit correlates with the cumulative temperature and the total amount of photosynthesis that has translocated to the fruit up to that temperature.

\section{4) Energy input to greenhouse}

Factors affecting the temperature of the greenhouse in tomato cultivation may be solar heat, heat transfer from the wall, air blast / ventilation, mist, and transpiration of plants (Matsuo et al., 2014) In this simulation, the input energy $P(\mathrm{~kJ})$ necessary for cultivation was taken as heating, cooling, and dehumidifying using an air conditioner used for night temperature control.

$$
P(t)=P_{\text {hot }}(t)+P_{\text {cool }}(t)+P_{\text {def }}(t)
$$

\section{Simulation}

\subsection{Simulation conditions}

A dynamic simulator to predict the growth and yield of cultivated tomato in the Asian monsoon area was constructed. This simulator was described by the programming tool Simulink. Simulink, one of the Matlab products, is a graphical programming environment for modelling, simulating and analysing dynamical systems. Therefore, it is possible to analyse phenomena according to the time series of tomato cultivation with this simulator. The constructed simulator makes it possible to evaluate the influence of changes in weather conditions and operating conditions on yield and growth conditions. In this study, the authors simulated the change in yield of greenhouse tomatoes due to the difference in weather conditions for each Asian region by using this cultivation simulator considering growth conditions. The crop growth conditions and energy of greenhouse tomato production in several Asian monsoon areas (Figure 4) were also evaluated.

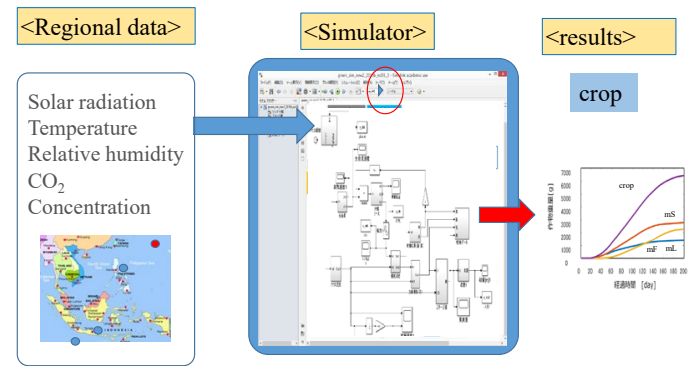

Figure 4. Tomato cultivation simulator

In the simulation, it was assumed that the amount of photosynthesis produced by leaves was simply the yield at a constant rate. In addition, the accumulated temperature affects the growth of tomatoes (Kita et al., 2014). Therefore, when the integrated temperature reaches a certain value, it is assumed that the integrated value of photosynthesis up to that point becomes the yield. The $\mathrm{CO}_{2}$ concentration was set to $400 \mathrm{ppm}$, the same as the concentration in the atmosphere. This is because air in greenhouse is always ventilated due to the high temperature in the house in summer. In winter, $\mathrm{CO}_{2}$

\begin{tabular}{|c|c|}
\hline Item & Value \\
\hline - Plant & Tomato \\
\hline - Area & $\begin{array}{l}\text { Tokyo, Taipei, Bangkok, } \\
\text { Jakarta, }\end{array}$ \\
\hline $\begin{array}{l}\text { - Cultivation appropriate } \\
\text { temperature }\end{array}$ & $25-30^{\circ} \mathrm{C}$ \\
\hline $\begin{array}{l}\text { - Control temperature } \\
\text { at night }\end{array}$ & $15^{\circ} \mathrm{C}$ \\
\hline $\begin{array}{l}\text { - Integrated temperature of } \\
\text { cultivation }\end{array}$ & $1000^{\circ} \mathrm{C}$ day \\
\hline - $\mathrm{CO}_{2}$ concentration & $400 \mathrm{ppm}$ \\
\hline - Crop yield & $\begin{array}{c}\sum m F(\mathrm{t}) \\
\text { (while Integrated } \\
\text { temperature) }\end{array}$ \\
\hline
\end{tabular}
concentration is controlled by using exhaust gas from kerosene combustion boiler. Simulation conditions are shown in Table 1.

Table 1. Simulation conditions

\subsection{Weather conditions of each area in cultivation}

The weather data used for analysis used the weather data service (Weatherbase, 2018). Figure 5 shows the temperature change during the daytime by region. It can be seen that Tokyo has seasonal variations but Indonesia has a constant temperature throughout the year. This 
figure also shows the optimum temperature for tomato cultivation during the day and the temperature during the night. In this simulation, the temperature of the green house was adjusted by air conditioning so that the temperature inside the greenhouse would be within the appropriate temperature each season, and the energy required at that time was calculated.
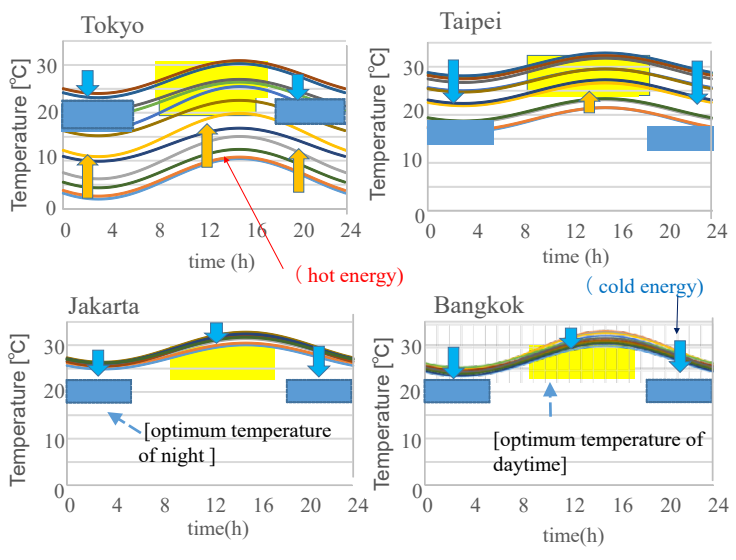

Figure 5. Daytime temperature transition in each region

Figure 6 shows the transition of the temperature, the amount of solar radiation, and the humidity for each month. These are required for calculation for photosynthesis. According to this figure, the temperature in Southeast Asia is high throughout the year, and in Taipei and Tokyo, the temperature varies depending on the season. As to solar radiation, it turns out that the amount of solar radiation is high in summer season in Tokyo. Furthermore, all areas except Tokyo have high humidity, which is effective for opening and closing pores, but it is expected that the temperature control will be difficult. Temperature-solar radiation graph shows that the amount of winter solar radiation to temperature tends to be small in Taiwan, suggesting the difficulty of cultivation management.

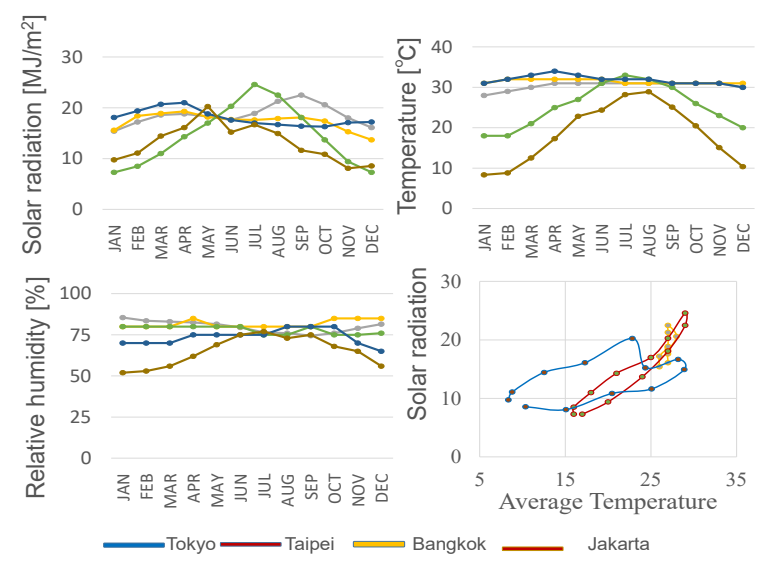

Figure 6. Transition of weather conditions in each area

\section{Results and Discussion}

Figure 7 shows the difference in monthly photosynthetic rate in each region of Asia. According to this, it is understood that the photosynthetic rate is high in the high temperature area, and the hot area is more advantageous if the temperature can be properly managed.
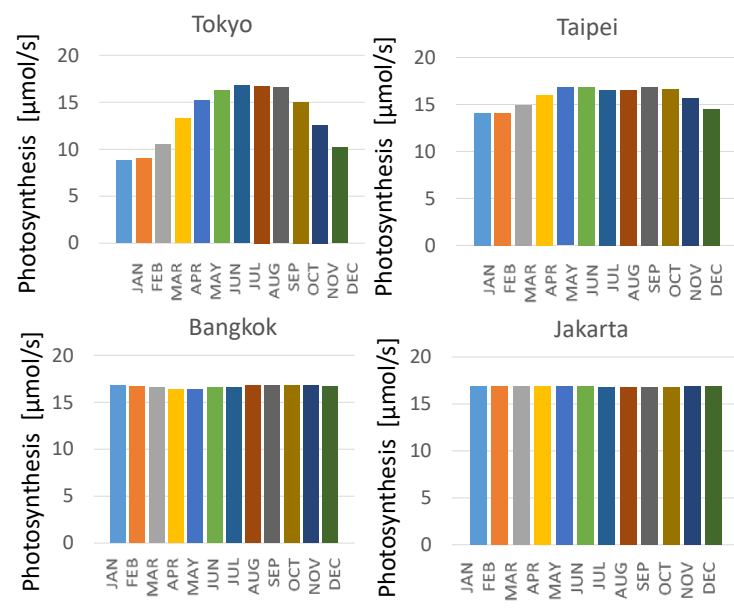

Figure 7. Calculated photosynthetic rate in each area

Figure 8 shows the cultivation period, that is, the number of days until the cumulative temperature of tomato cultivation reaches $1000^{\circ} \mathrm{C}$ in each Asian region, at each month when planting starts. From this figure, it can be understood that the number of cultivation days is shorter in each Asian region than in Tokyo. It is suggested that this is advantageous for the vegetative growth period at the early stage of cultivation, but is disadvantageous at the reproductive growth period during the late cultivation period when the fruits are enlarged. When the cultivation period is short, the integrated amount of photosynthesis decreases, which is considered to affect the tomato yield.

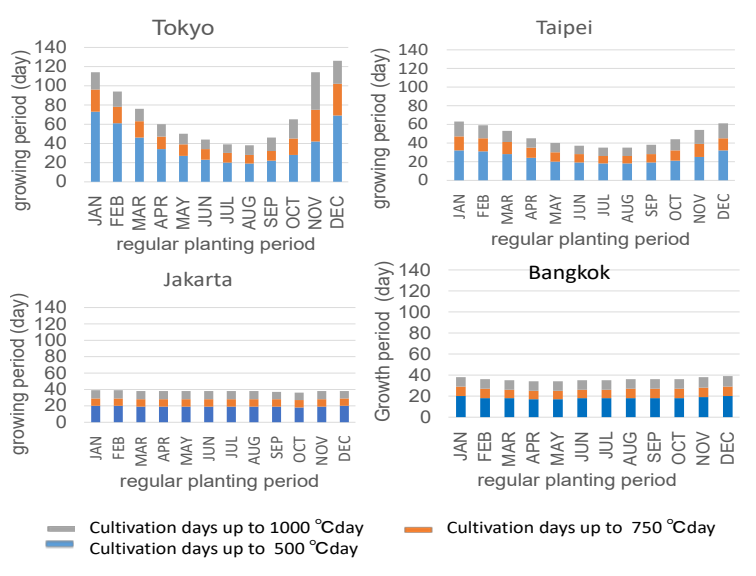

Figure 8. Caluclated cultivation period in each area

Figure 9 compares seasonally the amount of integrated photosynthesis in each region. Thus, it can be seen that although the photosynthetic rate is high in areas where the 
temperature is high throughout the year, the yield is reduced by the influence of high temperature. Therefore, it is suggested that it is necessary to increase the number of plants in cultivation and to reduce the growth rate of fruits in the future.

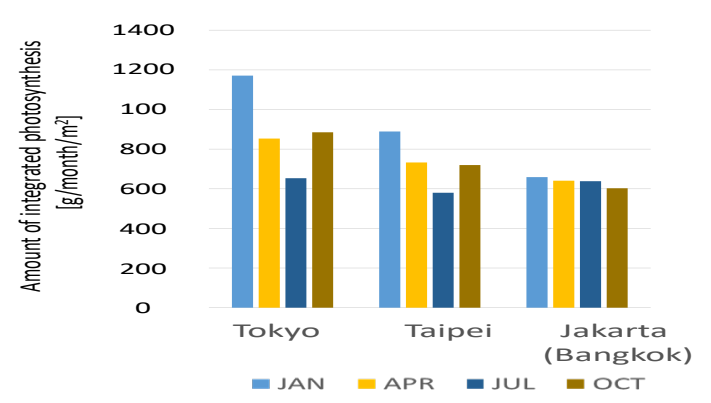

Figure 9. Calculated integrated photosynthesis in each area

Figure 10 is a comparison of the energy required for cultivation in each area, such as night time cooling and heating. According to this, energy for night cooling is particularly large, and from the viewpoint of energy efficiency per yield, it is considered that measures to effectively remove heat such as a heat shield sheet are necessary in the future.

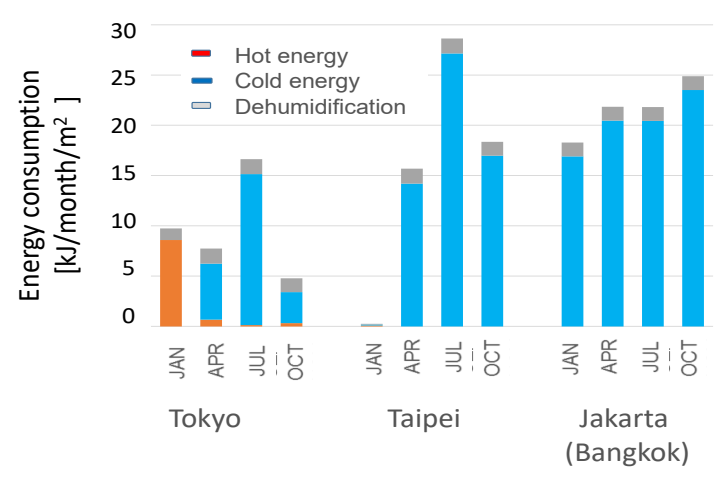

Figure 10. Calculated energy consumption in each area

\section{Conclusion}

In this study, the authors evaluated the crop growth conditions and energy of greenhouse tomato production in several Asian monsoon areas. In these evaluations, a cultivation simulator considering growth conditions was used. As a result, the difficulty of greenhouse tomato production under high temperature and humidity conditions in Asia and the differences in crop growth conditions among these regions could be clarified by this analysis. In the future, it was suggested that it would be necessary to reduce the temperature of the greenhouse while maintaining the amount of photosynthesis.

\section{Acknowledgements}

This research was supported by grants from R\&D matching funds on the field for Knowledge Integration and innovation, Development of Asian monsoon model plant factory system promoting innovation of information system and production system of agriculture, forestry and fisheries and food industry. The authors express our deep appreciation to these parties concerned.

\section{References}

Jones, J. W., E. Dayan, L. H. Allen, H. Van Keulen, and H. Challa; "A Dynamic Tomato Growth and Yield Model (Tomgro)," Transactions of the ASAE, 34, 0663-0672 (1991)

Kim, S. Y. and J. H. Lieth; "A Coupled Model of Photosynthesis, Stomatal Conductance and Transpiration for a Rose Leaf (Rosa hybrida L.), " Annals of Botany, 91, 771-781 (2003)

Kita, N., I. Hirose, T. Kitaura, and T. Sugiyama; "A Novel Hydroponic Tomato Cultivation Snystem That Enables Year Round Production with High Yield by Integrating Single-to-tripl and Multiple Truss Cropping Systems," Japanese Society of Agricultural Technology Management, 20, 139-147 (2014)

Kurosaki, H., H. Ohmori, Y. Iwasaki, and M. Takaichi; "Development of a Robot for Spraying a Fruit-set Reagent in a Tomato Cultivation System with Low Node-order Pinching and High Density Planting," The Japanese Society of Agricultural Machinery and Food Engineers, 76, 541-548 (2014)

Matsuo, S., Y. Hirako, Y. Iwasaki, and H. Umeda: "The Optimum Design of the Air-conditioning System of a Plant Factory with a High-efficient Water Use in Arid Area by Computer Simulation," EICA, 18, 52-59 (2014)

Nakano, M.; "Current State of Japanese Agriculture and Development of Plant Factory," The transactions of the Institute of Electrical Engineers of Japan, 136, 340-343 (2016)

Weatherbase : http://www.weatherbase.com/ (2018) 